\section{oluo mental}

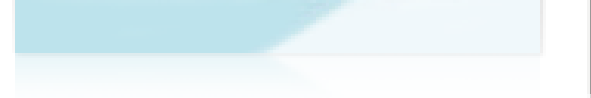

\section{Salud Mental}

ISSN: 0185-3325

perezrh@imp.edu.mx

Instituto Nacional de Psiquiatría Ramón de la

Fuente Muñiz

México

Prospéro-García, Oscar; Méndez Díaz, Mónica; Alvarado Capuleño, Ilia; Pérez Morales, Marcel;

López Juárez, Jehú; Ruiz Contreras, Alejandra E.

Inteligencia para la alimentación, alimentación para la inteligencia

Salud Mental, vol. 36, núm. 2, marzo-abril, 2013, pp. 101-107

Instituto Nacional de Psiquiatría Ramón de la Fuente Muñiz

Distrito Federal, México

Disponible en: http://www.redalyc.org/articulo.oa?id=58226224002

Cómo citar el artículo

- Número completo

- Más información del artículo

- Página de la revista en redalyc.org

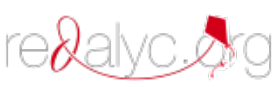

Sistema de Información Científica

Red de Revistas Científicas de América Latina, el Caribe, España y Portugal

Proyecto académico sin fines de lucro, desarrollado bajo la iniciativa de acceso abierto 


\title{
Inteligencia para la alimentación, alimentación para la inteligencia
}

\author{
Oscar Prospéro-García, ${ }^{1}$ Mónica Méndez Díaz, ${ }^{1}$ llia Alvarado Capuleño, ${ }^{1}$ Marcel Pérez Morales, ${ }^{1}$ \\ Jehú López Juárez, ${ }^{1}$ Alejandra E. Ruiz Contreras ${ }^{2}$
}

Artículo original

\section{SUMMARY}

Eating is a behavior oriented to get the energy necessary for the organism to survive and to contend with the demands of its environment. Food, besides of energy, provides structure and function, as amino acids are converted into structural or secretion proteins or enzymes. These proteins are synthesized following a strict genetic code. Variants in the genome happen frequently, but only those changes that result in a poor adaptive phenotype are well documented. There are other changes that may go unnoticed due to culture influence, and they may be seen as adaptive because they seem to favor individuals in the short-term. A child that overeats and becomes overweighed is culturally appreciated as a healthy child. However, systematic studies have shown that these feeding styles influenced by culture, in the longterm, result on an irreversible damage to the individual.

Food selection also depends on the functioning of homeostatic and hedonistic systems. The homeostatic system involves the hypothalamus that includes nuclei that promote both appetite and satiety. The hedonic system is constituted by the ventral tegmental area and the nucleus accumbens. Stimulation of the ventral tegmental area induces the release of dopamine into the nucleus accumbens, making the individual to experience pleasure. This system also interacts with the hypothalamic systems that promote appetite.

As it can be seen, food intake is regulated by diverse cerebral systems that are under the influence of one another. Failure in one of these systems may lead the subject to a compulsive, or defective, food intake. We have allowed media and mercantilist interests to govern our diet, instead of allowing our brain and its systems to do it. We should have psycoeducation as a priority in medicine to improve our capacity to select better quality food to eat, without compromising the pleasure of eating.

Key words: Reward system, hypothalamus, prefrontal cortex, amygdala, insula, orbitofrontal cortex.

\section{RESUMEN}

Comer es una conducta dirigida a conseguir la energía para llevar a cabo las funciones que mantienen al organismo y le permiten contender contra las demandas del medio.

Debido a que nuestro organismo evolucionó dentro de un ambiente con escasez de alimentos, los genes que nos adaptaron al medio fueron los que promueven el almacenamiento y optimización de los nutrientes, así como aquellos que promueven la habilidad de generar estrategias de cacería y otras conductas orientadas a ese objetivo. Estos mecanismos fisiológicos y bioquímicos incluyen una amplia variedad de genes, desde aquellos que codifican para enzimas que almacenan el glucógeno hasta enzimas que sintetizan o degradan a los neurotransmisores. Diversos sistemas cerebrales regulan la ingestión del alimento: El homeostásico involucra al hipotálamo lateral como promotor de la ingestión de alimento por medio de neuronas orexinérgicas y MCHérgicas, al núcleo arcuato que sintetiza y libera neuropéptido $Y$ y al péptido relacionado al gen agouti y como promotor de la saciedad a través de la POMC y del CART. Diferentes hormonas y proteínas hipotalámicas participan en la función del sistema hedónico compuesto por el área ventral tegmental y el núcleo accumbens, produciéndose un diálogo entre los sistemas homeostásico y hedónico. Otros sistemas cerebrales que participan son la amígdala y el lóbulo de la ínsula que promueven la selección de los alimentos con base en la experiencia. La corteza prefrontal participa en la preferencia por los alimentos y la toma de decisiones tales como qué, cuándo y dónde comer. Es importante reconocer que los sistemas neuroquímicos que regulan la ingestión del alimento también participan en funciones cognitivas y que la falla en estos sistemas afecta la forma en que el individuo elige su alimentación y, a su vez, el estado cognitivo del sujeto. Por lo tanto, la psicoeducación para regular los hábitos alimenticios debe ser una prioridad en el campo de la medicina.

Palabras clave: Sistema de reforzamiento, hipotálamo, corteza prefrontal, amígdala, ínsula, corteza órbitofrontal.

Grupo de Neurociencias: Laboratorio de Canabinoides, Departamento de Fisiología, Facultad de Medicina. Universidad Nacional Autónoma de México. 2 Laboratorio de Neurogenómica Cognitiva, Departamento de Psicofisiología, Facultad de Psicología. Universidad Nacional Autónoma de México.

Correspondencia: Dr. Oscar Prospéro-García. Departamento de Fisiología, Facultad de Medicina, Universidad Nacional Autónoma de México. Apdo. Postal 70-250, 04510, México, DF. Tel: (52-55) 5623 2509. Fax: (52-55) 5623 2241. E-mail: opg@unam.mx

Recibido: 5 de marzo de 2012. Aceptado: 16 de octubre de 2012. 


\section{INTRODUCCIÓN}

El acto de alimentarse es la obtención de energía que el predador realiza de la presa. Comer es una conducta dirigida a conseguir la energía adecuada y suficiente para llevar a cabo las funciones que mantienen al organismo con vida y lo ayudan a funcionar, de tal manera que pueda contender con las demandas del medio. Comer es, entonces, imprescindible para sobrevivir y mejor aún, para vivir con ventaja ante las presiones de la selección.

Se calcula que el homínido que dio origen al hombre moderno se originó aproximadamente hace 150 mil años. Las presiones de selección en África, como lo sugiere el descubrimiento del cráneo de Herto, en Etiopía, determinaron que el humano fuera un organismo con las características suficientes para adaptarse a todos los ambientes existentes en nuestro planeta. ${ }^{1}$ Es así que la maquinaria genotípica y fenotípica que nos conforma en la actualidad tiene al menos 150 mil años de antigüedad. Las mutaciones y recombinaciones en el genoma producen sujetos con variaciones génicas que, expuestos a la selección natural, participan de un flujo génico y una deriva génica, que finalmente son las encargadas de preservar y cambiar las proporciones de las variaciones.
En este espectro de variaciones, mutaciones debilitantes o polimorfismos que fortalecen al individuo, hay cambios que pasan desapercibidos para las concepciones culturales. Uno de estos eventos es la ingestión elevada de alimento. Los estudios sistemáticos han mostrado que, lejos de beneficiar al individuo, a la larga resulta en un daño irreversible que limita la calidad de vida y la longevidad. ${ }^{2}$ Así, la apreciación de que el niño que come abundantemente y está en sobrepeso u obeso, está sano, es una muestra de una concepción errónea de la salud propiciada por la cultura. Asimismo, en diversas familias se cree que si el niño duerme y ronca, está descansando. El ronquido es un síntoma que frecuentemente acompaña a la obesidad y que indica evidentemente un problema respiratorio del sujeto durmiente, con el consecuente sufrimiento del organismo a nivel cardiovascular, pulmonar y cerebral. ${ }^{3} \mathrm{Su}$ consecuencia conductual es que el sujeto está somnoliento durante el día y no puede ejecutar eficientemente las tareas que la sociedad le demanda. El ronquido no es territorio exclusivo de los obesos, pero es muy frecuente en ellos. Así que la medicina ha demostrado que estar en sobrepeso o francamente obeso, facilita el desarrollo de diversas enfermedades que no sólo reducen la calidad de vida sino que se vuelven una carga económica para la familia y la sociedad. ${ }^{4}$

Cuadro 1. Ejemplo de genes que participan en procesos cognitivos y en ingestión de alimento y almacenaje de glucosa y lípidos

\begin{tabular}{|c|c|c|c|}
\hline Gen & Proteína & Función & Proceso en el que participa \\
\hline GAD1 (2q31) & $\begin{array}{l}\text { Ácido glutamato descarboxilasa } \\
1 \text { (GAD67) }\end{array}$ & Síntesis de glutamato & $\begin{array}{l}\text { Memoria, atención, control del movi- } \\
\text { miento }\end{array}$ \\
\hline CHAT (10q11.2) & Colin-o-acetil-transferasa (CHAT) & Síntesis de acetilcolina & $\begin{array}{l}\text { Atención, memoria, sueño MOR, tono } \\
\text { muscular }\end{array}$ \\
\hline $\mathrm{DBH}(9 \mathrm{q} 34)$ & Dopamina-beta-hidroxilasa (DBH) & Síntesis de noradrenalina & Vigilia, alerta, atención \\
\hline DDC (7p 12.2) & $\begin{array}{l}\text { Descarboxilasa de los l-aminoáci- } \\
\text { dos aromáticos (AADC) }\end{array}$ & Síntesis de dopamina & $\begin{array}{l}\text { Hedonismo, cognición, control del } \\
\text { movimiento }\end{array}$ \\
\hline CAMK2A (5q32) & $\begin{array}{l}\text { Calcio-calmodulina II alfa } \\
\text { (CaMKIIA) }\end{array}$ & $\begin{array}{l}\text { Facilita la liberación de neurotransmisores } \\
\text { Activa factores promotores de la transcripción }\end{array}$ & $\begin{array}{l}\text { Promoción de la memoria de largo } \\
\text { plazo }\end{array}$ \\
\hline PRKACA (19p13.1) & $\begin{array}{l}\text { Proteína cinasa A subunidad alfa } \\
\text { catalítica (PKA) }\end{array}$ & $\begin{array}{l}\text { Activación de canales y de factores promoto- } \\
\text { res de la transcripción }\end{array}$ & $\begin{array}{l}\text { Activación de sistemas neuronales y } \\
\text { promoción de memoria de largo plazo }\end{array}$ \\
\hline CREB $1(2 q 34)$ & $\begin{array}{l}\text { Proteína de unión al elemento de } \\
\text { respuesta al AMPc (CREB) }\end{array}$ & Factor promotor de la transcripción & $\begin{array}{l}\text { Facilita procesos de memoria y apren- } \\
\text { dizaje }\end{array}$ \\
\hline HCRT (17q21) & Orexinas/hipocretinas & $\begin{array}{l}\text { Activación de diversos núcleos promotores de } \\
\text { la vigilia y de la corteza prefrontal } \\
\text { Activación de las neuronas dopaminérgicas } \\
\text { del ATV }\end{array}$ & $\begin{array}{l}\text { Alerta } \\
\text { Atención } \\
\text { Promoción de la sensación hedónica } \\
\text { producida por el alimento }\end{array}$ \\
\hline $\operatorname{LEP}(7 q 31.3)$ & Leptina & $\begin{array}{l}\text { Inhibición de núcleos promotores de la inges- } \\
\text { tión de alimento. } \\
\text { Inhibición de las células dopaminérgicas del ATV } \\
\text { Facilitación de la actividad del hipocampo }\end{array}$ & $\begin{array}{l}\text { Sensación subjetiva de saciedad. Re- } \\
\text { ducción de la sensación de hedonis- } \\
\text { mo producida por el alimento } \\
\text { Facilita los procesos de memoria }\end{array}$ \\
\hline GYS1 (19q13.3) & Glucógeno Sintasa & Síntesis de glucógeno & Almacén de glucosa \\
\hline GPAM (10q25.2) & Glicerol-3-fosfato-aciltransferasa & Síntesis de triglicéridos & Almacén de lípidos \\
\hline AGPAT2 (9q34.3) & $\begin{array}{l}\text { 1-Acil-glicerol-3-fosfato-O-acil- } \\
\text { transferasa } 2\end{array}$ & Síntesis de triglicéridos & Almacén de lípidos \\
\hline
\end{tabular}

Nota. Estos son sólo ejemplos de la existencia de los genes que participan en los procesos cognitivos, en las funciones ejecutivas, en la toma de decisiones, en el control del apetito y la saciedad y en el almacenaje de glucosa y lípidos. 
Inteligencia para la alimentación, alimentación para la inteligencia

Sabemos que nuestro organismo evolucionó en un momento en que las presiones de la selección incluían la escasez de los alimentos. Así que el organismo del humano parece que tenía un balance entre los genes que participan en regular funciones ejecutivas y que intervienen en generar estrategias para conseguir el alimento y los que facilitan su almacenaje en el cuerpo. Dentro de los primeros incluimos a los que participan en procesos de la memoria, en las habilidades para crear herramientas y los de las habilidades sociales. Por ejemplo, genes que codifican las enzimas que sintetizan o degradan a los neurotransmisores como el glutamato, la acetilcolina, el GABA, con sus respectivos receptores, por mencionar sólo algunos ${ }^{5}$ (cuadro 1). Entre los segundos, están los genes que se han especializado en facilitar el almacenaje de los nutrientes, por ejemplo, almacenar glucógeno o lípidos (cuadro 1). De esta manera es entendible que organismos que gastan gran cantidad de calorías para conseguir el alimento, y el que obtienen es exiguo, se benefician de tener genes que los ayuden a almacenar. Pero los genes que parecen participar más directamente en la generación de estrategias adaptativas, parecen estar bajo una gran demanda constantemente. Así que aparentemente se han seleccionando a aquellos que facilitan el desarrollo de mejores estrategias, entre otras las de obtención del alimento.

En este contexto, estos genes "previsores" propiciaron que el humano domesticara animales y plantas y creara espacios físicos de almacenamiento. Así pasamos de la cacería y la recolección exhaustiva con el consumo inmediato, a la domesticación de animales y de plantas que fueron reproducidos en cautiverio los unos y en plantíos las otras, para su consumo programado. Los genes previsores aparecieron y se fijaron rápidamente en el humano, por lo que el alimento ha proliferado gracias al refinamiento de estrategias de obtención y almacenamiento en espacios físicos, sin que los genes que participan en el almacenamiento hayan modificado su eficiencia. A consecuencia de este nuevo balance se puede inferir que el humano tiene una naturaleza vulnerable a la obesidad.

Dentro de los sistemas que están involucrados en la selección de los alimentos, se cuenta a los sentidos que detectan sabores, aromas, texturas e incluso sonidos que a lo largo de la experiencia se han identificado como asociados al beneficio energético del alimento. Asimismo, el sistema hedónico participa en proveerle al sujeto una sensación subjetiva de placer al ingerir un alimento que resulta benéfico para el organismo. El desbalance homeostásico que nos lleva a desear comer algo y el alimento que nos provee de una experiencia sensual, está matizado por el placer que nos brinda el sistema de reforzamiento. El placer no es un estímulo, es un constructo que el cerebro establece para garantizar la repetición de la conducta. El placer es una consecuencia de la sensualidad de los estímulos. Su capacidad para afectar el gusto, el olfato, la vista o el tacto, o todos ellos simultáneamente o en secuencia. Por ejemplo, en la ingestión de alimento el humano disfruta desde la presentación del mismo hasta el olor, el sabor y la textura. Hay momentos en que se disfruta incluso del sonido. Por ejemplo, un pan, una lechuga, una manzana o unas tostadas crujientes abren el apetito. Todos estos son estímulos que, al final, tendrán una forma de estimular al sistema de reforzamiento y el cerebro generará una sensación subjetiva de placer.

\section{SISTEMAS CEREBRALES QUE REGULAN LA INGESTIÓN DE ALIMENTO}

Sistema homeostásico. Básicamente aquí nos referimos al hipotálamo. Esta estructura cerebral que apenas pesa cuatro gramos en el humano controla el estado homeostásico en que se encuentra el sujeto. Entre otros procesos fisiológicos regula el hambre y la saciedad. Los núcleos principalmente involucrados en promover el hambre y la saciedad son: una parte del núcleo arcuato, las neuronas que sintetizan y liberan el neuropéptido $Y$ y el péptido relacionado al gen agouti. Asimismo, el hipotálamo lateral que contiene las células orexinérgicas y las MCHérgicas. Las primeras sintetizan y liberan orexinas A y B; las segundas, la hormona concentradora de melanina $(\mathrm{MCH})$. Ambas estirpes neuronales promueven la ingestión de alimento. Por el otro lado está el grupo neuronal del núcleo arcuato que sintetiza el transcrito regulado por la cocaína y la anfetamina (CART), promueve la saciedad y la proteína pro-opio-melano-cortina (POMC), que también reduce la ingestión de alimento. En el estómago se libera la GHrelina que promueve el apetito, afectando a las células que sintetizan y liberan neuropéptido Y. Asimismo, el tejido adiposo libera leptina la que inhibe a las células productoras de neuropéptido $Y$. El péptido $Y Y$, liberado por el colon, inhibe a su vez la ingestión de alimento, afectando al hipotálamo (figura 1).

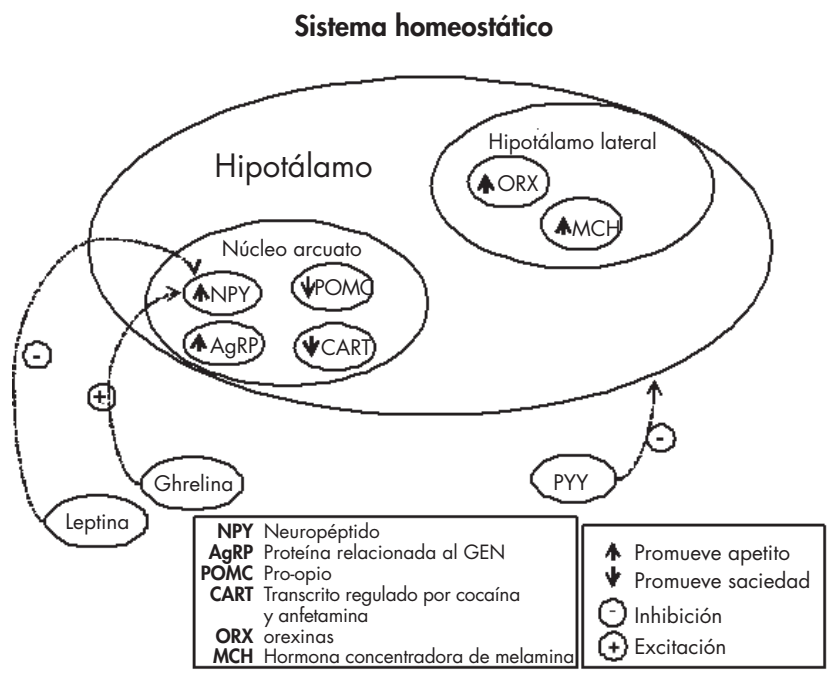

Figura 1. llustración esquemática del sistema homeostásico. Se ha simplificado con fines didácticos. Se ilustra las interacciones entre los núcleos y las moléculas y los resultados de estas interacciones en cuanto al apetito y a la saciedad. 


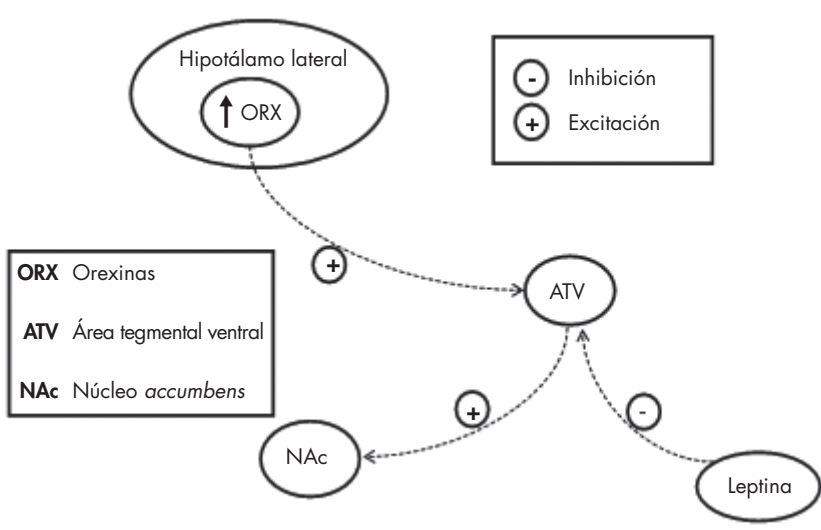

Figura 2. Esquema del sistema hedónico. Aquí se ilustran las interacciones de los sistemas promotores del apetito y los de la saciedad con el hedónico.

Sistema hedónico. Básicamente es el sistema de reforzamiento. Está compuesto por el área tegmental ventral (ATV) y el núcleo accumbens (NAc). La estimulación del ATV promueve la liberación de dopamina en el NAc y esto trae como consecuencia una sensación de placer para el sujeto. ${ }^{6}$ Los sistemas hipotalámicos que facilitan el apetito, como las orexinas, activan al ATV. Así que cuando experimentamos hambre y cuando estamos comiendo las neuronas orexinérgicas estimulan al sistema de recompensa y se activa el componente hedónico. Por otro lado, cuando se secreta la leptina porque es estimulada por los lípidos que ingerimos en el momento, ésta, como dijimos, reduce la actividad de las neuronas del núcleo arcuato que liberan al neuropéptido Y y reduce también la actividad del ATV. Como podemos ver, hay un diálogo muy activo entre el sistema de la homeostasis y el del hedonismo (figura 2).

\section{Sistemas cerebrales del cuidado}

La amígdala y el lóbulo de la ínsula. Se sabe que estas dos estructuras cerebrales participan en diversas funciones, entre ellas en la ingestión de alimento. Son sistemas que se encargan de su cuidadosa selección basados especialmente en la experiencia.

La amígdala es un conglomerado de núcleos que están en el parénquima del lóbulo temporal. El lóbulo de la ínsula es una parte de la corteza cerebral que se encuentra entre el lóbulo frontal y el temporal, dicho sea esto muy esquemáticamente.

El lóbulo de la ínsula y la amígdala están anatómicamente conectados con proyecciones del núcleo del tracto solitario (NTS). Este es un núcleo que regula la percepción de los sabores, ya que los nervios de los pares craneales VII, IX y X, que recogen los sabores en la lengua, se proyectan hacia él. El NTS también se proyecta al hipotálamo lateral. Los sabores, a través del NTS, promueven la activación de las células orexinérgicas facilitando el apetito, y afectando al lóbulo de la ínsula y la amígdala crean la sensación subjetiva de la seguridad del alimento. Lo contrario puede ocurrir si el alimento está descompuesto o contaminado y es capaz de hacer daño.?

La corteza prefrontal. Tiene diversas funciones en la selección del alimento. Por ejemplo, la corteza órbitofrontal participa en la selección de un alimento sobre otro. Las neuronas de esta región se activan proporcionalmente más cuando el sujeto prefiere un alimento apetitoso sobre otro. ${ }^{8}$

El tálamo. En dicha acción participan tanto los núcleos del tálamo como los intralaminares, el centromediano y el parafascicular. Estos núcleos se activan para inhibir la respuesta ante el estímulo que produce el menor refuerzo, o sea el menos apetitoso, ante la expectativa de uno de mayor refuerzo, el más apetitoso. ${ }^{9}$

Los sistemas ejecutivos: La toma de decisiones. Por otro lado la corteza prefrontal también cumple con la función de tomar la decisión de ingerir el tipo de alimento y el lugar en donde se ingiere. En estos mecanismos tenemos implícita la toma de decisiones en la obtención e ingestión de alimento frente a la amenaza de un predador y asimismo el tipo de alimento; por ejemplo, ingerir grasa saturada vs. insaturada. Actualmente sabemos que la grasa saturada produce déficit en los procesos cognitivos como el aprendizaje y la memoria, ${ }^{10}$ mientras que los insaturados (Omega 3 y 6) no sólo mejoran la cognición sino que protegen en contra del deterioro cognitivo. ${ }^{11}$ En animales de experimentación y en humanos la obesidad reduce la capacidad de realizar tareas de aprendizaje que incluyen la toma de decisiones, la memoria y el control de la inhibición, entre otros procesos cognitivos. ${ }^{12,13}$ Esto puede ser el resultado de cambios en el metabolismo y la neurotransmisión glutamatérgica que se producen en el hipocampo a consecuencia de una dieta alta en grasas. ${ }^{14}$ En este contexto, se ha observado que la restricción calórica en ratas obesas induce un aumento de las subunidades NR2A y NR2B de los receptores NMDA glutamatérgicos, y con ello mejoría en los procesos cognitivos (figura 3).$^{15}$

Regulación de los sistemas ejecutivos. En éstos participan la corteza cerebral, en particular la 3a. circunvolución fron-

\section{Regulación de sistemas ejecutivos}

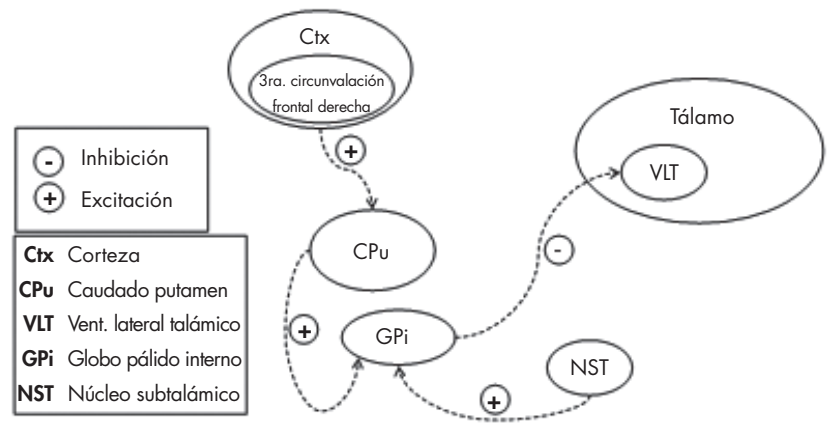

Inhibición del sistema ejecutivo-motor

Figura 3. Ilustración esquemática del sistema de control de los sistemas ejecutivos. Los componentes neuroanatómicos que regulan el control inhibidor de la conducta. 


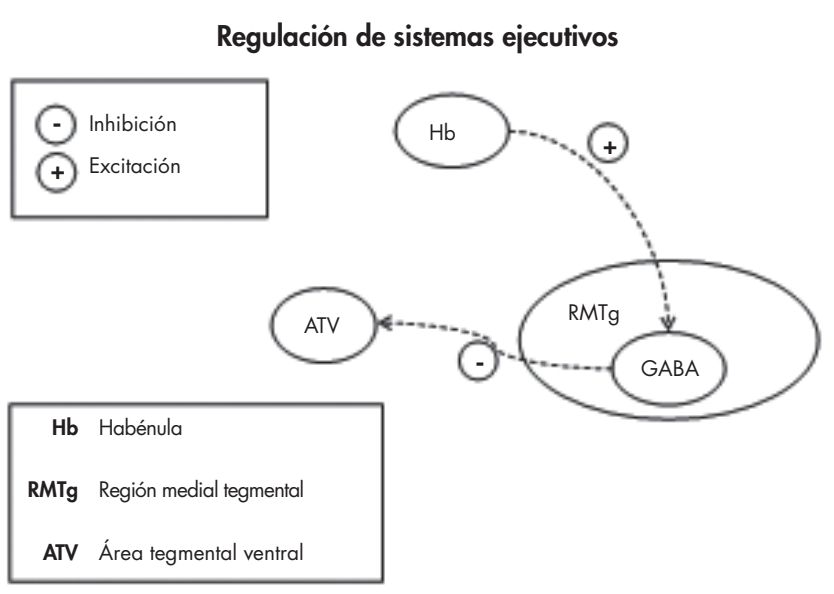

Inhibición de la conducta

Figura 4. Esquema de los componentes subcorticales que participan en la inhibición de la conducta.

tal derecha (que interactúa con el núcleo subtalálamico) y el globo pálido interno. ${ }^{16}$ Ambos, que son parte de los núcleos de la base, hacen que se inhiba el tálamo, en particular su núcleo ventrolateral, que es parte del sistema ejecutivo-motor, lo que inhibe a su vez la conducta motora. Asimismo, la habénula participa en la activación de una serie de neuronas GABAérgicas localizadas en la región medial tegmental (RMTg), situada caudalmente respecto del ATV, a la cual inhiben. ${ }^{17}$ De esta manera, el sujeto es capaz de inhibir su conducta y de atenuar su motivación por consumir un determinado alimento (figura 4).

\section{Las hormonas y los neurotransmisores que regulan la ingestión de alimento también regulan la cognición}

Las orexinas aumentan la excitabilidad de la corteza prefrontal, sugiriendo que facilitan su función. ${ }^{18}$ Las orexinas activan también a las células colinérgicas del cerebro basal anterior las cuales activan a la corteza prefrontal y al hipocampo. Esto conduce a la activación de los procesos de atención y de memoria. De hecho, en las ratas los antagonistas del receptor OX1R, que es receptor a orexina A, interfieren con el aprendizaje de tareas espaciales cuando se administran en el hipocampo. ${ }^{19,20}$ También se ha documentado que la administración intravenosa o nasal de orexina A a monos Rhesus privados de sueño durante $36 \mathrm{~h}$, reduce los efectos de tal privación y mejora el desempeño cognitivo en una tarea de memoria a corto plazo. ${ }^{21}$ Por otra parte, la administración directa de leptina al hipocampo facilita el aprendizaje de tareas espaciales y el desarrollo de señales bioeléctricas asociadas con el aprendizaje, como la potenciación o la depresión de largo plazo (LTP o LTD, respectivamente). ${ }^{22}$ Asimismo, los ratones con deficiencia del receptor a la leptina $(\mathrm{db} / \mathrm{db})$ tienen dificultades para aprender tareas espaciales y desarrollan pobremente la LTP y la LTD. ${ }^{23}$

\section{La teoría de la mente y la selección de la dieta}

La teoría de la mente se refiere a la capacidad que tenemos de representar y atribuir estados emocionales y pensamientos a nosotros mismos y a los demás. ${ }^{24}$ Esta habilidad nos permite la interacción social y es de crucial importancia en el establecimiento de relaciones afectivas, de amistad y sexuales. ${ }^{25}$ Debido a esta habilidad podemos tener un aprendizaje vicario; es decir, aprender del modelaje de nuestros pares o nuestros educadores y cuidadores primarios. ${ }^{26}$ Se ha dado un gran progreso en el entendimiento de los sistemas cerebrales que sustentan este aprendizaje vicario con la descripción de las neuronas espejo. ${ }^{27}$ Los humanos tenemos que aprender diversas habilidades para poder contender con las demandas del medio exitosamente: caminar, hablar, aprender, memorizar, poner atención, incluso dormir a los horarios establecidos. Todos estos procesos tienen cierto determinismo neurobiológico matizado por usos y costumbres de nuestra cultura. Dentro de estas habilidades está la de establecer el concepto de alimento y la posibilidad de comerlo. ${ }^{28}$ Es decir, hacer la diferencia entre lo que se come o no y si dada las circunstancias se puede o no comer. Esta toma de decisiones requiere de la integración de las funciones de todas las estructuras del cerebro mencionadas en este texto y tal vez más. Así que el establecimiento de la dieta básica que un individuo tiene ocurre en una etapa temprana del desarrollo mediante el aprendizaje, como ocurre con el lenguaje. La dieta, al igual que el lenguaje, tiene sus matices culturales y su expresión local. Comer tortillas de maíz o pan de trigo es una opción que tiene su sesgo. Muchos europeos en México prefieren comer pan con sus alimentos en vez de tortillas; mientras que muchos mexicanos preferimos éstas. En la teoría de la mente suponemos que el que come tortillas disfruta, se siente bien y considera que es parte importante de su dieta. Así que establecer la dieta que después decimos que es de nuestra predilección requiere de una serie de procesos cognitivos que se establecen con el aprendizaje y permanecen estables, en su mayor parte, a lo largo de nuestra vida. Creemos que la dieta, como el lenguaje, puede enriquecerse. Si tenemos un léxico básico que distingue entre una región de México y otra, asimismo la dieta distingue entre las regiones mexicanas y nos distingue obviamente de otros países. La dieta es difícil de cambiar, como es difícil de cambiar nuestro lenguaje. Podemos agregar otro idioma a nuestras habilidades y forzarnos a hablarlo si vivimos en el país en donde ese otro lenguaje se habla, pero siempre tendremos el materno. Nos podemos adaptar a los usos y costumbres de otros países, pero no por ello olvidamos lo que aprendimos en etapas críticas del desarrollo. De esta manera, difícilmente sustituiremos nuestra dieta por otra. Ésta es una Teoría de la Alimentación. ${ }^{28}$ El cerebro aprende a nutrirse con un tipo de dieta y si el sujeto enferma, por ejemplo, de un síndrome metabólico, cambiarle la dieta será una 
tarea titánica, como pedirle a esa persona que se comunique en inglés cuando toda su vida ha hablado español. La Teoría de la Alimentación sugiere que la dieta que utilizamos para nutrirnos es el producto de una serie de procesos cognitivos que, llegada a cierta edad, han ayudado a que dicha dieta esté establecida a tal punto que el sujeto puede solicitar los mismos platillos incluso diariamente (como arroz, frijoles, salsas y tortillas de maíz, en México).

\section{El chef del cerebro}

"-Entonces, chef, ¿Qué recomienda comer para tener un excelente cerebro? Chef: - Pescado, pescado y pescado". Sabemos que suena exagerado, porque lo es. Pero queremos enfatizar que incluir pescado en la dieta es de gran importancia para mantener a nuestro cerebro saludable. ¿Qué otros alimentos facilitan la salud del cerebro y facilitan los procesos cognitivos? Frutas como kiwi, fresas y arándanos, semillas como nueces y cacahuates. Otros productos: champiñones, espárragos, aguacate, espinacas, huevos, lechugas, aceitunas. En fin, hay una enorme variedad de alimentos que nos permiten proveer al cerebro de los nutrientes adecuados para su funcionamiento óptimo y con ello queremos decir con sus procesos cognitivos en estado óptimo (En el cuadro 2 hay una guía de los alimentos y qué sustancias nos aportan).

\section{CONCLUSIÓN}

Como se puede apreciar, los sistemas cerebrales encargados de la regulación de la ingestión de alimento son diversos. Es importante reconocer que los sistemas que regulan más directamente la ingestión de alimento también promueven los procesos cognitivos. Por lo mismo, es plausible convocar al reconocimiento de una Teoría de la Alimentación. Si esta propuesta es válida, quiere decir que debemos promover una dieta ventajosa desde los primeros años de vida. De otra manera, de acuerdo a esta teoría, una vez establecidos los trazos de memoria y consolidado el aprendizaje de la

Cuadro 2. Ejemplos de alimentos que facilitan los procesos cognitivos.

Alimento Contenido nutricional

Función beneficiada

Salmón y otros pescados; frutas como kiwi; Ácidos grasos, como Omega-3 semillas como nueces y de calabaza.

Cúrcuma longa (planta que es el ingrediente Cúrcuma que le brinda el color amarillo al curry)

Cebolla, manzana, brócoli, cereza, uva, col Flavonoides roja, cerveza y vino tinto

Carne de cerdo y res, hígado, riñones, pescado, huevo, cereales, pan integral, leche, queso, coliflor, alubias, plátano, espinaca, berro, pepino, zanahoria

Yema de huevo, pollo, hígado de pavo, todas la vísceras animales, lechuga, col, soya, garbanzos, lentejas, arroz, cacahuates

Carne, pescado, huevo, productos lácteos, espárragos, garbanzos, lentejas, cacahuates, soya

Huevo, leche, cereales integrales, chocolate, avena, dátiles, cacahuates, plátano, calabaza, semillas de girasol

Perejil y espinacas crudas; lácteos, carnes (cruda y ahumada), frutos secos: nueces, almendras y GABA)
Complejo B (vitamina B 1-B 12)

Colina: genera acetilcolina

Efectos benéficos sobre la atención y la memoria, mejora el sueño de movimientos oculares rápidos.

Fenilalanina: genera dopami- Como NE: Facilita la vigilia y el alertamiento, la atención y la na (DA), noradrenalina (NE) y memoria. Reduce el dolor.

adrenalina $(A)$

Como DA: facilita la sensación de placer y regula el control motor.

Como A: mejora las respuestas de defensa y huida.

Triptófano: genera serotonina Como 5-HT: Reduce el riesgo a la depresión, aumenta las (5-HT) y melatonina (Mel) sensaciones de placer, reduce el estrés y el dolor. Como Mel: beneficia los ciclos circadianos.

Glutamina (genera glutamato Como glutamato: Mejora la memoria, la atención, el control motor, regula el miedo y la sensación de placer. Como GABA: reduce la ansiedad y promueve el sueño.

Nota. Estos son sólo unos ejemplos de alimentos que mejoran los procesos cognitivos. 
utilización de una dieta, las posibilidades de sustituirla se reducen. Por otro lado, la falla en alguno de estos sistemas, por ejemplo, la del sistema hedónico o la del sistema de regulación de los sistemas ejecutivos, puede llevar a un sujeto a consumir alimento de manera compulsiva ${ }^{29}$ propiciando así el sobrepeso y la obesidad.

\section{AGRADECIMIENTOS}

Este trabajo se realizó con el apoyo de los donativos IN220712 de DGAPA-UNAM a OPG, el donativo 80148 del CONACyT a MMD y el donativo IN217311 de DGAPA-UNAM a AERC.

\section{REFERENCIAS}

1. Clark D, Beyene Y, WoldeGabriel G, Hart W et al. Stratigraphic, chronological and behavioural contexts of Pleistocene Homo sapiens from Middle Awash, Ethiopia. Nature 2003;423:747-752.

2. Mair W, Dillin A. Aging and survival: The genetics of life span extension by dietary restriction. Annu Rev Biochem 2008;77:727-754.

3. Katz ES, D'Ambrosio CM. Pediatric obstructive sleep apnea syndrome. Clin Chest Med 2011;31:221-234.

4. Cawley J, Meyerhoefer C. The medical care costs of obesity: An instrumental variables approach. J Health Eco 2011 Oct 20 [Epub ahead of print]

5. Rankinen T, Bouchard C. Genetics of food intake and eating behavior phenotypes in humans. Annu Rev Nutr 2006;26:413-434.

6. Méndez Díaz M, Ruiz Contreras AE, Prieto Gómez B, Romano A et al. El cerebro y las drogas, sus mecanismos neurobiológicos. Salud Mental 2010;33:451-456.

7. Bermúdez-Rattoni F, Ramírez-Lugo L, Gutiérrez R, Miranda MI. Molecular signals into the insular cortex and amygdala during aversive gustatory memory formation. Cell Mol Neurobiol 2004;24:25-36.

8. Tremblay L, Schultz W. Relative reward preference in primate orbitofrontal cortex. Nature 1999;398:704-708.

9. Minamimoto T, Hori Y, Kimura M. Complementary process to response bias in the centromedian nucleus of the thalamus. Science 2005;308:1798-1801.

10. Naqvi AZ, Harty B, Mukamal KJ, Stoddard AM et al. Monounsaturated, trans, and saturated Fatty acids and cognitive decline in women. J Am Geriatr Soc 2011;59:837-843.

11. Zhang $\mathrm{W}$, Li P, Hu X, Zhang F et al. Omega-3 polyunsaturated fatty acids in the brain: metabolism and neuroprotection. Front Biosci 2011;17:2653-2670.
12. Jurdak N, Lichtenstein AH, Kanarek RB. Diet-induced obesity and spatial cognition in young male rats. Nutr Neurosci 2008;11:48-54.

13. Mobbs O, Iglesias K, Golay A, Van der Linden M. Cognitive deficits in obese persons with and without binge eating disorder. Investigation using a mental flexibility task. Appetite 2011;57:263-271.

14. Valladolid-Acebes I, Merino B, Principato A, Fole A et al. High-fat diets induce changes in hippocampal glutamate metabolism and neurotransmission. Am J Physiol Endocrinol Metab 2012;302:E396-E402.

15. Yilmaz N, Vural H, Yilmaz M, Sutcu R et al. Calorie restriction modulates hippocampal NMDA receptors in diet-induced obese rats. J Recept Signal Transduct Res 2011;31:214-219.

16. Aron AR, Robbins TW, Poldrack RA. Inhibition and the right inferior frontal cortex. Trends Cogn Sci 2004;8:170-177.

17. Balcita-Pedicino JJ, Omelchenko N, Bell R, Sesack SR. The inhibitory influence of the lateral habenula on midbrain dopamine cells: Ultrastructural evidence for indirect mediation via the rostromedial mesopontine tegmental nucleus. J Comp Neurol 2011;519:1143-1164.

18. Li B, Chen F, Ye J, Chen X et al. The modulation of orexin A on HCN currents of pyramidal neurons in mouse prelimbic cortex. Cereb Cortex 2010;20:1756-1767.

19. Akbari E, Naghdi N, Motamedi F. Functional inactivation of orexin 1 receptors in CA1 region impairs acquisition, consolidation and retrieval in Morris water maze task. Behav Brain Res 2006;173:47-52.

20. Akbari E, Naghdi N, Motamedi F. The selective orexin 1 receptor antagonist SB-334867-A impairs acquisition and consolidation but not retrieval of spatial memory in Morris water maze. Peptides 2007;28:650-656.

21. Deadwyler SA, Porrino L, Siegel JM, Hampson RE. Systemic and nasal delivery of orexin-A (Hypocretin-1) reduces the effects of sleep deprivation on cognitive performance in nonhuman primates. J Neurosci2007;27:14239-14247.

22. Wayner MJ, Armstrong DL, Phelix CF, Oomura Y. Orexin-A (Hypocretin-1) and leptin enhance LTP in the dentate gyrus of rats in vivo. Peptides 2004;25:991-996.

23. Harvey J, Solovyova N, Irving A. Leptin and its role in hippocampal synaptic plasticity. Prog Lipid Res 2006;45:369-378.

24. Premack D, Woodruff G. Chimpanzee problem-solving: a test for comprehension. Science 1978;202:532-535.

25. Abu-Akel A, Shamay-Tsoory S. Neuroanatomical and neurochemical bases of theory of mind. Neuropsychologia 2011;49:2971-2984.

26. Bandura A. Social learning theory. New York: General Learning Press; 1977.

27. Umiltà MA, Kohler E, Gallese V, Fogassi L et al. I know what you are doing. A neurophysiological study. Neuron 2001;31:155-165.

28. Allen JS. "Theory of food" as a neurocognitive adaptation. American J of Human Biol 2012;24:123-129.

29. Volkow ND, Wang GJ, Baler RD. Reward, dopamine and the control of food intake: implications for obesity. Trends Cogn Sci 2011;15:37-46.

Artículo sin conflicto de intereses 